\title{
Relationship between subtypes and symptoms of ADHD, insomnia, and nightmares in connection with quality of life in children
}

This article was published in the following Dove Press journal:

Neuropsychiatric Disease and Treatment

5 September 2017

Number of times this article has been viewed

Julia Grünwald'

Angelika Anita Schlarb ${ }^{2}$

'Department of Psychology, Faculty of Science, University of Tübingen, Tübingen, ${ }^{2}$ Department of Clinical Psychology and Psychotherapy, Faculty of Psychology and Sports Science, University of Bielefeld, Bielefeld, Germany
Correspondence: Angelika Anita Schlarb Department of Clinical Psychology and Psychotherapy, Faculty of Psychology and Sports Science, University of Bielefeld, Bielefeld, Germany

Tel +49521 1066962

Email angelika.schlarb@uni-bielefeld.de
Objectives: This study examined the links between sleep disorders and subtypes of attention deficit-hyperactivity disorder (ADHD-inattention, ADHD-combined, ADHD-hyperactive/ impulsive) in childhood. We set up a hypothetical model linking different symptoms of both disorders to construct the underlying and shared pathways. By examining a sample of children with ADHD we firstly tested parts of the model.

Methods: A total of 72 children with symptoms of ADHD (aged 6-13 years; 79.2\% boys) were diagnosed according to the Diagnostic and Statistical Manual of Mental Disorders, fifth edition and the International Classification of Sleep Disorders, third edition in regards to ADHD and sleep disorders via standardized parent-rated questionnaires. Additionally, quality of life (QoL) was assessed. Overall, 46 children fulfilled the criteria of ADHD and were medication-naive. Results: On average, the whole sample had clinically elevated total scores of the Children's Sleep Habits Questionnaire in the validated German version (CSHQ-DE), indicating an increased prevalence of sleep disorders in children with ADHD. In accordance to our hypothetical model, children with primarily hyperactive-impulsive ADHD showed the highest CSHQ-DE scores. Moreover, we found a high impact for insomnia in this subgroup and a high comorbid load for the mutual occurrence of insomnia and nightmares. Furthermore, QoL was reduced in our whole sample, and again intensified in children with comorbid insomnia and nightmares.

Conclusion: We verified an elevated occurrence of sleep disorders in children with ADHD and were able to link them to specific subtypes of ADHD. These results were in line with our hypothetical model. Moreover, we found a clinically reduced QoL in mean for the whole sample, indicating the strong impact of ADHD in the lives of affected children, even intensified if children exhibited comorbid insomnia and nightmares. These results should be kept in mind regarding the treatment and therapy of this subgroup of children. Specific treatment strategies should be considered for these children.

Keywords: impulsivity, hyperactivity, inattention, sleep disorders, childhood

\section{Introduction}

Attention deficit-hyperactivity disorder (ADHD) is one of the most frequently diagnosed disorders in childhood and adolescence with a worldwide prevalence of $5.29 \%$. ${ }^{1,2}$ A recent meta-analysis confirmed this pattern of results and reports prevalance rates of $5.9 \%-7.1 \%{ }^{3}$ The typical pattern consists of several different heterogeneous symptoms, which interact complexly. ${ }^{4,5}$ The core symptoms are inattention, impulsiveness, and hyperactivity, which have to occur cross-situationally. ${ }^{6,7}$ Nearly two thirds of all children with ADHD have comorbid disorders, especially externalizing behavior problems; also anxiety, depression, and obsessive-compulsive disorders are 
common. ${ }^{8-10}$ Already at preschool age, a high comorbid rate is found, that even increases with age. ${ }^{1}$ In addition, ADHD persists in adulthood more often, if patients suffer from comorbid disorders. ${ }^{11}$

Potential comorbid disorders of ADHD in childhood are sleep problems. This comorbidity is controversially discussed, but there is a growing evidence which supports this link. ${ }^{12,13}$ Jan et al concluded for example that there seems to be a link between symptoms of ADHD and sleep disorders. ${ }^{14}$ However, they report that the results strongly depend on the instruments that assess sleep variables. In parents' reports, relationships between ADHD and sleep are found frequently (mostly night waking, bedtime resistance, difficulty initiating sleep, daytime sleepiness). In contrast, studies that use objective measurements as actigraphy or polysomnography show inconsistent findings (see review of Jan et $\mathrm{al}^{14}$ ). Recently, a meta-analysis on the use of actigraphy in monitoring sleep in ADHD children came to the conclusion that actigraphy is an objective tool in sleep monitoring for ADHD children. In their analysis, the authors confirmed that children with ADHD showed higher mean activity during sleep, a moderately altered sleep pattern, but no differing sleep duration. ${ }^{15}$ In a study combining subjective and objective measurements, Owens et al ${ }^{16}$ concluded that children with ADHD experienced shorter actual sleep time and fewer, but significantly longer, sleep interruptions than healthy children (aged 6-14 years) as well as more daytime sleepiness. They concluded that maybe there are subgroups of children who have specific sleep phenotypes whose presentation might be characteristic of an intrinsic ADHD-mediated hyperarousal at bedtime. The authors also emphasize the fact that another great influence factor might be parent-child interactions before sleeping time, which also could account for perceived bedtime problems. ${ }^{16}$ Therefore it is of great importance to diagnose ADHD as well as sleep disorders cautiously, and to distinguish the main causes of symptomatology to decide if treatment of sleep disorders is the primary goal or treatment of ADHD. Kirov et al report evidence that sleep disturbances represent an important aspect of ADHD symptomatology, including motor restlessness and increased nocturnal motoricity. ${ }^{17}$ Furthermore, they assumed a rapid eye movement (REM) sleep pressure for children with ADHD, which is based on the neurobiological backgrounds of ADHD. ${ }^{18}$ Another mediating effect between sleep problems and ADHD symptomatology might be stimulant medication, which may produce sleep disturbances and changes in sleep architecture as well as deviations of brain maturation processes. ${ }^{10}$ However, the connection between stimulant medication and sleep in children with ADHD is far from being clearly understood. A recent longitudinal study proves no evidence for changes in sleep architecture after a 6-month period of methylphenidate medication. ${ }^{19}$

Rates for insomnia in childhood vary between $20 \%$ and $30 \% .^{13,20}$ The most frequently found sleep disorder in childhood is behavioral insomnia. ${ }^{20}$ These complaints are also frequent among children with ADHD. ${ }^{12,21,22}$ Gau et al reported that adolescents with ADHD in childhood had a higher risk of current and lifetime sleep problems. Moreover, they found that at least one psychiatric comorbid disorder increased the risk for insomnia and nightmares. ${ }^{23}$

Nightmares are the most frequent parasomnia in childhood and often developmentally associated with prevalences between $14 \%$ and $57.6 \% .^{24,25}$ They can result in a reduced sleep quality due to nightly wakings, reduced reduced daytime mental stability and self-esteem, as well as higher psychological strain, poorer attention, and reduced academic performance. ${ }^{26,27}$ Leung et $\mathrm{al}^{26}$ argued that insomnia rates are increased in children with nightmares. They assume that children could have insomnia due to fears of experiencing nightmares or due to difficulties in falling asleep after nightmares. ${ }^{26}$ Stress seems to play a considerable role in the development of nightmares: they seem to result out of emotional conflicts during the day, maybe reflecting and processing those experiences. ${ }^{26}$ In 2010 , Chiang et al concluded that both children with combined ADHD (ADHD-C) and primarily hyperactive/impulsive ADHD (ADHD-HI) had increased rates of nightmares. ${ }^{28}$ Li et $\mathrm{al}^{29}$ conducted a study with 6,359 Chinese children and concluded that - besides other results - symptoms of insomnia and parasomnia as well as daytime consequences were significantly associated with nightmares in children. Moreover, they found a significant association between hyperactivity, frequent temper outbursts, and nightmares. ${ }^{29}$

An important comorbid disorder of sleep problems, especially nightmares and insomnia, is anxiety disorders. A potential connecting link seems to be the state of REM sleep, which is associated with the consolidation of emotional memories with negative valence as well as with many affective disorders, such as anxiety and depression. ${ }^{30}$ An interesting study was conducted by Whalen et $\mathrm{al}^{31}$ in 2016. They examined a clinical sample of 292 children with early-onset psychopathology, who took part in a prospective longitudinal study (Preschool Depression Study). The study provided evidence that difficulty in sleeping alone and prolonged sleep onset latency in preschool age were significant predictors for anxiety severity and depression symptomatology 6 years later. Interestingly, these 
variables did not predict ADHD symptomatology. To check if this connection was due to the clinical sample, the authors examined a sample of healthy preschoolers. In this healthy sample, parent-reported sleep onset latency and refusal to sleep alone predicted greater anxiety symptom severity, but not depression symptom severity or ADHD symptomatology. ${ }^{31}$ In a sample of 128 youth (aged 6-17 years) Alfano et al found a prevalence of $88 \%$ for youth experiencing at least one sleep-related problem. Furthermore, they reported a significant positive correlation between anxiety severity and sleep-related problems. ${ }^{32}$ This result could be reinforced by a study of Alfano et al in 2009, where they could prove that this connection was also visible in a nonclinical sample of children and adolescents. Their findings revealed significant results for depressive as well as anxiety symptoms. For anxiety symptoms, they found an association for all age groups with sleep problems. ${ }^{33}$ In a very recent study, Fletcher et $\mathrm{al}^{34}$ examined 90 school-aged children (aged 6-12 years) using the Children's Sleep Habits Questionnaire (CSHQ) as well as actigraphy as an objective measurement for 14 nights. They discovered a significant association between anxiety symptoms and current sleep problems (using the cut off of the CSHQ), measured by parent-rated questionnaires. Specifically, an association between increased parental concerns, sleep duration, daytime sleepiness, and sleep onset delay to generalized anxiety disorders was visible. For actigraphy results, only an association between night-to-night variability of sleep times and anxiety was found. ${ }^{34}$ Therefore, the links between anxiety and sleep problems should always be taken into cautious account in studies connecting sleep problems to other symptoms of psychopathology.

So far there is no established model with regard to the combined occurrence of ADHD, insomnia, and nightmares. Former approaches discuss a shared dysregulation of arousal. ${ }^{35}$ These approaches assume that children with ADHD have a dysfunction or dysregulation of arousal level and an increased risk for irregularities in their environment, for example, concerning their familial stability or irregular bedtimes. ${ }^{35}$ Those vulnerabilities in connection with ADHD symptomatology predispose those children to an increased risk of sleep disorders, particularly insomnia. Kirov and Brand report evidence that sleep problems might be related to ADHD subtype, namely ADHD-C. They debate shared pathways in neurobiological mechanisms for sleep regulation as well as ADHD psychopathology, namely, dopamine and noradrenaline deficits, as well as serotonin deficits, which are a precursor of melatonin. Based on these assumptions and the findings that REM sleep changes are common among children and adolescents with ADHD, they predicted in their neurochemical model that REM sleep overdrive may characterize sleep architecture in ADHD ${ }^{10}$ Recently, Virring et $\mathrm{al}^{36}$ could also prove that children with ADHD had more sleep disturbances and a larger percentage of REM sleep, as well as more sleep cycles. In their analysis, they did neither find associations to any comorbidities, nor to ADHD subtype presentation. ${ }^{36}$ Therefore, the influence between ADHD and sleep seems to be bidirectional and seems to constitute itself through neurobiological as well as daytime-related criteria due to irregularities in the environment.

Additionally, we expect those children to have an increased risk for nightmares. As discussed above, one possible underlying origin of nightmares is adverse daily experiences, which children with ADHD undergo far more frequently than healthy children. ${ }^{29,37}$ Furthermore, REM sleep neurobiology and dreaming are tightly coupled. And as discussed above, REM sleep changes are common among children and adolescents with ADHD. ${ }^{38}$ Therefore, we expect children with ADHD-C and ADHD-HI to show an elevated level of nightmares in comparison to children with inattentive ADHD (ADHD-I) symptoms. They experience more difficulties in their daily lives due to more frequent hyperactive and impulsive actions as well as more externalizing behavior problems. ${ }^{8,26,39}$ Figure 1 displays a hypothetical model concerning the relationship between ADHD, insomnia, and nightmares.

Another important component in children with ADHD is quality of life (QoL). A German sample of 721 children and adolescents with ADHD (age range 6-17) revealed a lower QoL in relation to a normative control sample for parent- as well as self-reports. However, the authors only found comorbid conduct problems as a responsible impact factor for this relationship. ${ }^{37}$ Already in 2005 Escobar et al found that QoL was rated worse in children diagnosed with ADHD than in healthy controls and even asthmatic children. The authors concluded that ADHD interferes with the daily lives of children and their environment even more than asthma (primarily in areas related to psychosocial functioning).$^{40}$ The reduction in QoL for children with ADHD is attributed to impairments in many areas like academic performance, behavior at school, peer relations, and family functioning. ${ }^{37,40}$ In a Canadian sample of 165 children with ADHD, a significant impact on different domains of healthrelated QoL was found. The more symptoms of ADHD children exhibited, the worse their psychosocial QoL was. The authors reported additionally that children with multiple comorbid disorders had a lower psychosocial QoL in different 


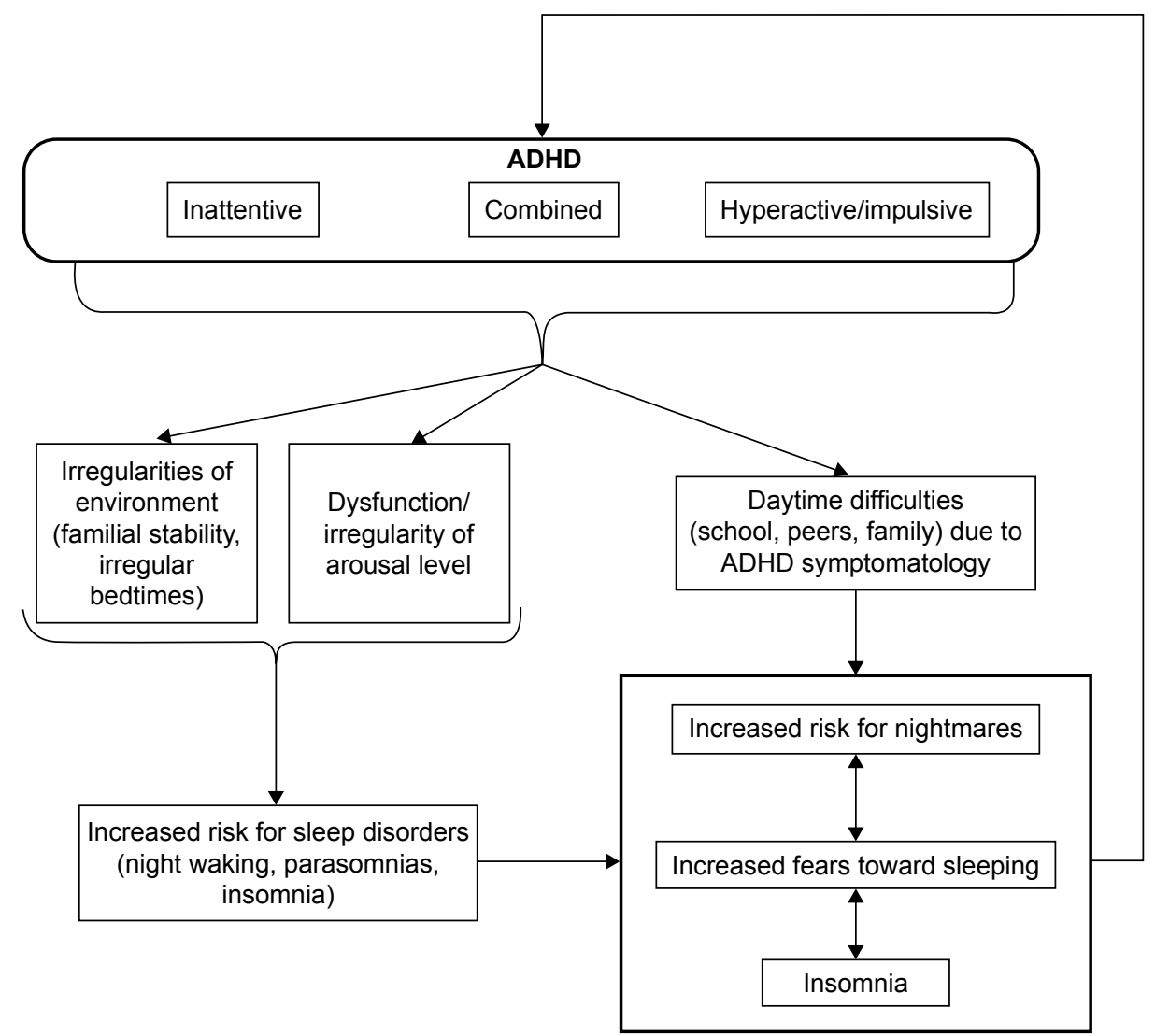

Figure I Hypothetical model relating symptoms of ADHD, specific environmental influences, and sleep disturbances. Abbreviation: ADHD, attention deficit-hyperactivity disorder.

domains (compared to children with ADHD without or with only one comorbid disorder). ${ }^{41}$ This was also reported by Escobar et al, who concluded that a higher risk of comorbid disorders could lower the QoL for children with ADHD compared to healthy children. ${ }^{40}$ Therefore, we assume that QoL is lowered in children with ADHD. If children exhibit insomnia or nightmares comorbid to ADHD, the QoL should be in addition negatively affected.

The aim of this study was to differentiate comorbid sleep disorders in children with ADHD, especially symptoms of nightmares and insomnia and relate them to QoL in these children and their subtype of ADHD.

We expect children with ADHD to show different sleep disorders, but specifically nightmares and insomnia, due to the above presented hypothetical model. Especially, we assume children with ADHD-HI and ADHD-C to display the highest rates of insomnia and nightmares. As children with those subtypes experience a high load of stress and difficulties during the day, we hypothesize them to have a lowered QoL, especially if they suffer from comorbid sleep disorders. If children exhibit insomnia symptoms and nightmares, we expect them to have the lowest QoL in comparison to others.

\section{Methods}

\section{Diagnostic measures}

Diagnostic measures included face-to-face interviews with parents as well as children (if age and understanding of the diagnostic situation existed) prior to inclusion in the study. All investigations were conducted by trained practitioners. All children completed the Hamburg-Wechsler Intelligence Test for Children IV. ${ }^{42}$ To assess ADHD symptomatology, we used the German "Fremdbeurteilungsbogen für hyperkinetische Störungen" (FBB-HKS) for parents in the standardized version from 2008, which is a subjective external assessment that includes the criteria of all three subtypes of ADHD. ${ }^{43}$ Diagnosis was carried out according to the Diagnostic and Statistical Manual of Mental Disorders, fifth edition (DSM-5) criteria cautiously after a diagnostic session and presence of all relevant information. For sleep disorders, we used the Children's Sleep Habits Questionnaire in the validated German version (CSHQ-DE). ${ }^{44}$ This questionnaire includes 48 parent-rated items. Computation of all eight scales results in a total score (sleep disturbance score). For evaluating symptoms of insomnia, we computed a sum score of the scales of 1 ) bedtime resistance (6 items), 
2) sleep onset delay (1 item), 3) sleep duration (3 items), 4) sleep anxiety (4 items), 5) night waking (3 items), and 6) daytime sleepiness ( 8 items) for suggestive insomnia. To test for potential nightmares, we used item no 47 "nightmares" of the Child Behavior Checklist ${ }^{45}$ and item no 23 of the CSHQ-DE "alarmed by scary dream" 44 to compute a sum score for nightmares, which we created according to the International Classification of Sleep Disorders, third edition (ICSD-3) criteria. ${ }^{46}$ To assess health-related QoL, we used the German "Questionnaire for Measuring Health-Related QoL in Children and Adolescents" (KINDL). KINDL is a validated questionnaire with six subscales composed of 24 items: 1) physical well-being, 2) emotional well-being, 3) self-esteem, 4) family, 5) friends, and 6) school. Raw scores are transformed to a range of 0-100 (most negative to most positive). The KINDL questionnaire is available for children, adolescents, and parents. In this study, we used the external parent-rated form. For comparisons, we used the norm sample of the German Kinder und Gesundheits survey, which was performed between 2003 and 2006 and collected representative norm data of children between 0 and 17 years concerning their physical and psychological well-being. ${ }^{47}$

For analysis, we only used parent-rated questionnaires to ensure equality of obtained data, independent of the age of the child. All variables of questionnaires were Likert-scaled.

\section{Study sample}

The sample consisted of 72 children with ADHD symptomatology and an intelligence quotient (IQ) > 82 ( $\mathrm{M}=106.85$; $\mathrm{SD}=12.86$ ). Children were between 6 and 13 years of age (mean age 8.61 \pm 1.65 ). We included children whose parents signed in at our outpatients clinics for diagnostic and/or treatment or consultation due to attention problems or ADHD symptomatology. Usually families were either sent by their pediatrician, by school advice, or seldomly by advice of other former participants. Participation in this study included the completion of the above questionnaires by parents. In addition, participation was absolutely voluntary. Furthermore, parents were adequately informed of the aims, methods, institutional affiliations of the psychologists, and any other relevant aspects of the study prior to the start of the study. They were informed that they had the right to refuse to participate in the study or to withdraw consent to participate at any time without reprisal. Psychologists ensured that the parents had understood the information; afterward, the psychologist sought the potential subjects' written informed consent. Parents gave their informed consent for participating in the treatment of our outpatients' clinic and research. All of them were patients of our outpatients' clinic. The study was conducted according to standard ethical guidelines as defined by the Declaration of Helsinki. Ethical approval for research in the outpatients' clinic was provided by the ethical board of the Bielefeld University.

\section{Statistical analyses}

For all analyses, the Statistical Package for Social Sciences (version 21.0; IBM Corporation, Armonk, NY, USA) was used. We tested for Gaussian distribution of all relevant variables using the Kolmogoroff-Smirnov test. As most variables were not normally distributed, we used nonparametric tests for our analysis to provide clarity of results and equality for comparisons of results.

Firstly, we conducted Spearman rho correlations to observe potential relationships between the variables of interest; subsequently, we conducted Kruskal-Wallis tests and Mann-Whitney $U$ tests. The level of significance was set at $\alpha \leq 0.05$.

\section{Results Sample characteristics}

A total of 52 children met all the criteria for ADHD: 15 were diagnosed with predominantly ADHD-I, 16 with predominantly ADHD-HI, and 21 with ADHD-C. The remaining 20 children were considered as having subthreshold ADHD. Overall, 9 children were medicated with stimulants. The subjects' gender, age, and IQ are shown in Table 1. No significant differences were observed between groups. To strengthen our results and to avoid potential biases in

Table I Gender, age, IQ, and medication in total and for all four diagnostic groups

\begin{tabular}{|c|c|c|c|c|c|c|}
\hline \multirow[t]{2}{*}{ Group } & \multirow{2}{*}{$\frac{\text { Sum }}{\mathbf{N}(\%)}$} & \multicolumn{2}{|c|}{ Gender } & \multirow{2}{*}{$\frac{\text { Age }}{M(S D)}$} & \multirow{2}{*}{$\frac{\mathrm{IQ}}{\mathrm{M}(\mathrm{SD})}$} & \multirow{2}{*}{$\frac{\text { Medication }}{\text { N (\%) }}$} \\
\hline & & Male & Female & & & \\
\hline Combined & $21(29.17)$ & 16 & 5 & $8.70(1.63)$ & 110.11 (12.86) & $2(9.52)$ \\
\hline Inattentive & I5 (20.83) & 11 & 4 & $8.27(1.79)$ & II 0.54 (I4.76) & $2(13.33)$ \\
\hline Hyperactive-impulsive & $16(22.22)$ & 14 & 2 & $8.69(1.99)$ & $102.80(12.55)$ & $4(25.00)$ \\
\hline Subthreshold & $20(27.78)$ & 20 & 0 & $8.58(1.26)$ & $104.75(10.95)$ & I (5.00) \\
\hline Total & $72(100)$ & 57 & 14 & $8.44(1.60)$ & 106.87 (12.59) & $9(12.50)$ \\
\hline
\end{tabular}

Abbreviations: M, mean; SD, standard deviation; IQ, intelligence quotient. 
results, we only analyzed the subgroups ADHD-C, ADHD-I, and ADHD-HI; furthermore, we removed medicated children from all analysis. Therefore, the analyzed sample comprised 46 children (ADHD-C: $n=19$; ADHD-I: $n=13$; ADHD-HI: $\mathrm{n}=12$ ).

To check for potential anxiety symptomatology, we used the scale anxious/depressed. In mean, our sample did not show clinically elevated scores in this scale $(\mathrm{M}=59.34$; $\mathrm{SD}=9.06$ ). An analysis for potential group differences between ADHD diagnostic groups also revealed no significant result $\left(\chi^{2}[2]=1.456 ; P=0.483\right)$, either for differences in the presence of insomnia ( $U=188.00, z=-0.107 ; P=0.928$ ) or presence of nightmares/insomnia $(U=198.00, z=-0.771$; $P=0.441$ ). Therefore, no differences in relation to anxiety/ depression symptomatology were present in this sample.

\section{Observed sleep problems in the sample} Correlational analysis between general symptoms of sleep and ADHD symptomatology

To gain an insight into the connection between sleep disorders and psychopathology in ADHD, we conducted Spearman rho correlations for the above mentioned sleep variables and the three core symptoms of ADHD, measured and standardized by FBB-HKS. As can be seen in Table 2, there are significant correlations between sleep and ADHD variables in two out of nine scales of the CSHQ-DE in different variations according to the measured ADHD symptomatology.

\section{Analysis according to diagnostic group}

To examine the incidence of sleep disorders in the subtypes of ADHD (Table 3), we next compared the observed mean of the sleep disturbance score of the CSHQ-DE to the cut off ( $\mathrm{M}=1.24)$ in terms of clinical significance: all analyzed groups scored above the cut off for clinical significance. Observable were higher scores for the groups ADHD-HI and ADHD-C, though the applied Kruskal-Wallis test did not reveal significant effects $\left(\chi^{2}[2]=1.411 ; P=0.494\right)$. The same approach was applied for the remaining subscales of the CSHQ-DE. No significant differences were observable, except for the scale parasomnias $\left(\chi^{2}[2]=6.343 ; P=0.042\right)$ and the scale sleep-disordered breathing $\left(\chi^{2}[2]=6.107 ; P=0.047\right)$. Subsequent analysis only revealed a significant difference in the Mann-Whitney $U$ test between the groups ADHD-I and ADHD-HI ( $U=31.00, z=-2.636 ; P=0.010)$ for the scale parasomnias.

\section{Analysis between ADHD, comorbid insomnia, and nightmares}

To test the specific hypothesis that children with ADHD-C and ADHD-HI exhibit more symptoms of insomnia, we rated those children as suffering from insomnia who scored $\geq 9.5$ in the sum score for insomnia, which were a total of 12 children $(27.3 \%)$ who were distributed among the diagnostic groups as follows: ADHD-I ( $\mathrm{N}=0 ; 0.0 \%)$, ADHD-HI ( $\mathrm{N}=6 ; 50.00 \%)$, and ADHD-C ( $=6 ; 31.58 \%)$. The performed Kruskal-Wallis test revealed significant differences $\left(\chi^{2}[2]=7.992 ; P=0.018\right)$ between groups. Post hoc tests showed a significant difference between ADHD-I and ADHD-HI ( $U=39.00, z=-2.865 ; P=0.035)$. Therefore, children with ADHD-HI suffered significantly more from insomnia than children with ADHD-I.

To analyze the frequency of nightmares in our sample, we computed the prevalence of nightmares and scary dreams. In the entire sample, $45.5 \%$ of the children showed symptoms of nightmares: $22.7 \%$ occassionally with peaks of 2-4 times per week, whereas $20.5 \%$ reported regular nightmares, fulfilling the diagnostic criteria for nightmares according to ICSD-2, and 2.3\% suffered severely from nightmares. ${ }^{46}$

To test if children with insomnia showed more symptoms of nightmares, we conducted a Mann-Whitney $U$ test

Table 2 Correlations between ADHD symptomatology and sleep problems (sample $n=44$ )

\begin{tabular}{lllll}
\hline CSHQ-DE scale & $\begin{array}{l}\text { Inattention } \\
\boldsymbol{r}(\boldsymbol{P})\end{array}$ & $\begin{array}{l}\text { Hyperactivity } \\
\boldsymbol{r}(\boldsymbol{P})\end{array}$ & $\begin{array}{l}\text { Impulsivity } \\
\boldsymbol{r}(\boldsymbol{P})\end{array}$ & $\begin{array}{l}\text { Total score } \\
\boldsymbol{r}(\boldsymbol{P})\end{array}$ \\
\hline Bedtime resistance & $-0.233(0.064)$ & $0.118(0.222)$ & $0.121(0.217)$ & $0.116(0.226)$ \\
Sleep onset delay & $-0.142(0.179)$ & $0.011(0.471)$ & $0.117(0.224)$ & $0.074(0.317)$ \\
Sleep duration & $0.009(0.478)$ & $0.011(0.472)$ & $0.175(0.127)$ & $0.021(0.445)$ \\
Sleep anxiety & $-0.148(0.167)$ & $0.151(0.164)$ & $-0.018(0.454)$ & $0.068(0.332)$ \\
Night waking & $-0.137(0.188)$ & $0.171(0.134)$ & $0.215(0.080)$ & $0.155(0.158)$ \\
Parasomnias & $-0.216(0.080)$ & $0.288(0.029 *)$ & $0.164(0.143)$ & $0.169(0.137)$ \\
Sleep-disorderd breathing & $0.070(0.327)$ & $0.431(0.002 *)$ & $0.266(0.040 *)$ & $0.289(0.029 *)$ \\
Daytime sleepiness & $-0.040(0.398)$ & $-0.141(0.184)$ & $0.094(0.275)$ & $0.017(0.456)$ \\
Sleep disturbance score & $-0.122(0.215)$ & $0.046(0.383)$ & $0.166(0.141)$ & $0.148(0.168)$ \\
\hline
\end{tabular}

Notes: $* P \leq 0.05 ; * * P \leq 0.01$. Positive significant correlations were evident for parasomnias and hyperactivity as well as for sleep disorderd breathing and hyperactivity, impulsivity and total score.

Abbreviation: ADHD, attention deficit-hyperactivity disorder. 
Table 3 Means and SDs for all scales of the CSHQ-DE with respect to the diagnostic groups

\begin{tabular}{|c|c|c|c|c|}
\hline Scale & $\begin{array}{l}\text { ADHD-I } \\
M(S D) \\
(n=\mid 3)\end{array}$ & $\begin{array}{l}\text { ADHD-HI } \\
M(S D) \\
(n=I 2)\end{array}$ & $\begin{array}{l}\text { ADHD-C } \\
M(S D) \\
(n=19)\end{array}$ & Kruskal-Wallis test \\
\hline Bedtime resistance & $1.23(0.28)$ & $1.36(0.39)$ & $1.27(0.49)$ & $\left(\chi^{2}[2]=2.782 ; P=0.249\right)$ \\
\hline Sleep onset delay & $1.31(0.63)$ & $\mathrm{I} .67(0.78)$ & $1.74(0.93)$ & $\left(\chi^{2}[2]=2.149 ; P=0.34 I\right)$ \\
\hline Sleep duration & $1.21(0.37)$ & $1.42(0.57)$ & $1.35(0.57)$ & $\left(\chi^{2}[2]=0.802 ; P=0.670\right)$ \\
\hline Sleep anxiety & $1.27(0.30)$ & $1.33(0.39)$ & $1.29(0.42)$ & $\left(\chi^{2}[2]=0.340 ; P=0.844\right)$ \\
\hline Night waking & I.I3 (0.29) & $1.42(0.63)$ & I. $32(0.4 \mathrm{I})$ & $\left(\chi^{2}[2]=3.505 ; P=0.173\right)$ \\
\hline Parasomnias & $1.09(0.11)$ & $\mathrm{I} .38(0.3 \mathrm{I})$ & $1.26(0.28)$ & $\left(\chi^{2}[2]=6.343 ; P=0.042\right)^{*}$ \\
\hline Sleep-disordered breathing & $1.00(0.00)$ & $1.10(0.16)$ & I. 17 (0.29) & $\left(\chi^{2}[2]=6.107 ; P=0.047\right)^{*}$ \\
\hline Daytime sleepiness & $1.76(0.46)$ & $1.65(0.43)$ & $1.56(0.46)$ & $\left(\chi^{2}[2]=1.366 ; P=0.505\right)$ \\
\hline Sleep disturbance score & $1.29(0.14)$ & $1.43(0.25)$ & $1.36(0.28)$ & $\left(\chi^{2}[2]=1.41 \mathrm{I} ; P=0.494\right)$ \\
\hline
\end{tabular}

Note: $* P \leq 0.05$.

Abbreviations: $M$, mean; SD, standard deviation; ADHD, attention deficit-hyperactivity disorder; ADHD-I, inattentive ADHD; ADHD-HI, hyperactive-impulsive ADHD; ADHD-C, combined ADHD; CSHQ-DE, Children's Sleep Habits Questionnaire in the validated German version.

and found a significant difference between ADHD children with and without insomnia $(U=111.50, z=-2.346 ; P=0.033)$. Therefore, children with insomnia suffered more from nightmares than children without insomnia. Afterward, we tested if there was a significant correlation between ADHD, insomnia, and signs of nightmares. The conducted Spearman rho correlation revealed a significant correlation $(r=0.358$; $P=0.009$ ).

Furthermore, we tested if nightmares were more frequent in a certain subtype of ADHD, but the conducted KruskalWallis test did not reach statistical significance $\left(\chi^{2}[2]=1.358\right.$; $P=0.507)$. The afterward conducted Spearman rho correlations revealed no significant correlation between nightmares and the sum score for ADHD $(r=0.115 ; P=0.230)$.

\section{Observed QoL in the sample}

To integrate our results in relation to QoL, we analyzed if children with ADHD had a lowered QoL in comparison to normative data, which could be confirmed (Table 4). ${ }^{47}$ Children with ADHD therefore suffer from a lower QoL.
For differences between children with ADHD with and without the comorbidity of sleep disorders, we found a heterogenous picture (Table 5). In the scale of psychological well-being, a significant difference between children suffering from nightmares compared to children without nightmares was observable $(U=55.50, z=-2.187 ; P=0.032)$.

\section{Discussion}

Our analysis of a sample of children with ADHD showed significant correlations between ADHD symptomatology and sleep problems in two out of nine scales of the CSHQ-DE with the most significant associations to hyperactivity symptoms. In addition, on average our sample showed clinically significant sleep problems - as measured by the sleep disturbance score of the CSHQ-DE. In detail, a total of 31.8\% children of our sample exhibited a sleep disturbance score above the cut off for clinical significant sleep disorders. Although there was no statistically significant difference between groups, children with ADHD-HI and ADHD-C had remarkably higher sum scores concerning sleep problems

Table 4 Means and SDs for all scales of KINDL with respect to the diagnostic groups and the normative data

\begin{tabular}{|c|c|c|c|c|}
\hline Scale & Norm & $\begin{array}{l}\text { ADHD-I } \\
M(S D) \\
(n=\mid 3)\end{array}$ & $\begin{array}{l}\text { ADHD-HI } \\
M(S D) \\
(n=12)\end{array}$ & $\begin{array}{l}\text { ADHD-C } \\
M(S D) \\
(n=19)\end{array}$ \\
\hline Physical well-being & 80.5 & $68.27 *(18.30)$ & $68.75 *(24.28)$ & $73.03 *(13.5 I)$ \\
\hline Psychological well-being & 82.3 & $81.73 *(9.01)$ & $73.96 *(14.56)$ & $77.30 *(8.89)$ \\
\hline Self-esteem & 70.8 & $59.09 *(15.48)$ & $71.88 *(12.64)$ & $66.67 *(16.74)$ \\
\hline Family & 79.8 & $75.00 *(8.84)$ & $69.79 *(14.06)$ & $66.45 *(15.34)$ \\
\hline Friends & 78.3 & $67.79 *(13.94)$ & $72.40 *(\mid 4.7 I)$ & $65.35 *(16.69)$ \\
\hline Daily/school functioning & 82.6 & $77.08 *(12.02)$ & $73.96 *(12.16)$ & $67.76 *(12.37)$ \\
\hline Total score & 79.0 & $70.99 *(8.33)$ & $71.79 *(10.12)$ & $69.39 *(8.72)$ \\
\hline
\end{tabular}

Notes: *A clinically significant reduction in QoL in comparison to normative control data. KINDL refers to the German "Questionnaire for Measuring Health-Related QoL in Children and Adolescents."

Abbreviations: $M$, mean; SD, standard deviation; ADHD, attention deficit-hyperactivity disorder; ADHD-I, inattentive ADHD; ADHD-HI, hyperactive-impulsive ADHD; ADHD-C, combined ADHD; QoL, quality of life. 
Table 5 Means and SDs for all scales of KINDL with respect to the diagnostic groups, sleep disorder, and the normative data

\begin{tabular}{|c|c|c|c|c|c|c|c|}
\hline \multirow[t]{2}{*}{ Scale } & \multirow[t]{2}{*}{ Norm } & \multicolumn{2}{|l|}{$\begin{array}{l}\text { ADHD-I } \\
\text { M (SD) }\end{array}$} & \multicolumn{2}{|l|}{$\begin{array}{l}\text { ADHD-HI } \\
\text { M (SD) }\end{array}$} & \multicolumn{2}{|l|}{$\begin{array}{l}\text { ADHD-C } \\
M(S D)\end{array}$} \\
\hline & & $\begin{array}{l}\text { SP } \\
(n=2)\end{array}$ & $\begin{array}{l}\text { No SP } \\
(n=I I)\end{array}$ & $\begin{array}{l}\text { SP } \\
(n=7)\end{array}$ & $\begin{array}{l}\text { No SP } \\
(n=5)\end{array}$ & $\begin{array}{l}\text { SP } \\
(n=8)\end{array}$ & $\begin{array}{l}\text { No SP } \\
(n=I I)\end{array}$ \\
\hline Physical well-being & 80.5 & $68.75^{*}(8.84)$ & $68.18 *(19.86)$ & $62.50 *(23.39)$ & $77.50 *(25.23)$ & $68.75 *(13.77)$ & $76.14 *(13.06)$ \\
\hline Psychological well-being & 82.3 & $87.50(0.00)$ & $80.68 *(9.46)$ & $69.64 *(16.70)$ & $80.00 *(9.27)$ & $78.13 *(6.68)$ & $76.7 \mid *(10.49)$ \\
\hline Self-esteem & 70.8 & $46.88^{*}(30.94)$ & $61.32 *(12.51)$ & $77.68 *(12.43)$ & $63.75 *(8.15)$ & $67.19 *(19.12)$ & $66.25^{*}(15.65)$ \\
\hline Family & 79.8 & $84.38(4.42)$ & $73.29 *(8.43)$ & $73.21 *(16.02)$ & $65.00 *(10.46)$ & $62.50 *(13.36)$ & $69.32 *(16.64)$ \\
\hline Friends & 78.3 & $71.88^{*}(13.26)$ & $67.05 *(14.44)$ & $71.43 *(18.70)$ & $73.75^{*}(8.15)$ & $63.02 *(20.92)$ & $67.05 *(13.72)$ \\
\hline Daily/school functioning & 82.6 & $84.38(22.10)$ & $75.63 *(10.40)$ & $72.32 *(15.25)$ & $76.25^{*}(6.85)$ & $67.19 *(14.47)$ & $68.18^{*}(11.34)$ \\
\hline Total score & 79.0 & $73.96 *(0.01)$ & $70.45^{*}(9.01)$ & $71.13 *(12.73)$ & $72.7 \mathrm{I} *(6.09)$ & $67.82 *(7.83)$ & $70.53^{*}(9.5 \mathrm{I})$ \\
\hline
\end{tabular}

Notes: *A clinically significant reduction in QoL in comparison to normative control data. KINDL refers to the German "Questionnaire for Measuring Health-Related QoL in Children and Adolescents."

Abbreviations: SD, standard deviation; ADHD, attention deficit-hyperactivity disorder; ADHD-I, inattentive ADHD; ADHD-HI, hyperactive-impulsive ADHD; ADHD-C, combined ADHD; QoL, quality of life; SP, sleep disorder.

than children with ADHD-I, which is in line with our above presented hypothetical model.

Specific symptoms of insomnia were found in $27.3 \%$ of all children, with a significant difference between children with the subtypes ADHD-I and ADHD-HI, indicating that children with ADHD-HI showed significantly more symptoms of insomnia than children with ADHD-I. This is in accordance to our hypothetical model, that hyperactive and impulsive symptomatology is associated with a higher impact of sleep problems, especially insomnia and nightmares.

We observed a high prevalence of children suffering from nightmares. However, no significant difference between ADHD subtypes could be found. Additionally, we found a significant difference between children suffering from ADHD and insomnia and those without insomnia: children with ADHD and insomnia suffered significantly more from nightmares than children with ADHD alone. These results are in accordance with the assumption of Leung and Robson who suggested that nightmares in children could provoke insomnia due to fears concerning sleep. ${ }^{26}$ Moreover, the correlation between nightmares and ADHD symptomatology can be seen in accordance to the hypothesis that stress plays an important role in the development of nightmares, assuming that higher ADHD symptomatology leads to increased stress in daily life.

As we expected and several other authors already reported, a clinically significant reduced QoL in our sample of children with ADHD, concerning all scales of the KINDL, was observable. ${ }^{37,40,41}$ Our study sample therefore showed a reduced QoL in all relevant areas in comparison to normative data. In addition, if children in this sample suffered from comorbid insomnia and nightmares, their QoL was reduced in comparison to children without those comorbidities. These results emphasize the importance of sleep disorders as comorbid disorders in ADHD which lead to significant losses in QoL in the affected children.

\section{Limitations}

Some limitations should be noted. First, the sample size of the subgroups of ADHD was small even if the total number of patients was acceptable. Further studies with larger subgroups should be initiated. Moreover, there was a predominance of males with $77.3 \%$ in our whole sample, which could have affected our results. However, this gender disparity is typically observed in ADHD subjects. For example, a recent study of Virring et al reports a gender disparity with $74 \%$ males. ${ }^{36}$ Our study sample therefore is in line with previous findings. However, gender disparity could be important for the link between sleep disorders and anxiety/depression. In our sample, we did not find these links, which have been previously described. ${ }^{30-34}$ One reason could be different sample characteristsics; for example, a study of Whalen et al had a male percentage of $52 \%$, which is almost equal gender distribution. ${ }^{31}$

Second, no objective measurements were included. Subjective measurements including the child's perspective would add information about the severity level of sleep disorders and give additional information about potential directions and associations of the disorder. ${ }^{48,49}$ Actigraphy as an objective measurment would give further information. ${ }^{15}$ In addition, sleep diaries would give more detailed information about various sleep parameters such as sleep onset latency, sleep duration, nightmare frequency, and also stress as well as resistance offered in going to bed..$^{50}$

Overall, we could confirm that children with ADHD showed an elevated level of sleep disturbances. We also found a specific pattern of sleep disorders related to the different 
subtypes of ADHD. These results are in line with our above presented hypothetical model. Furthermore, we found that on average the QoL of all children of our study was significantly reduced in a clinical manner, indicating that these children had a lowered QoL in multiple domains - as friends, family, school, or physical and psychological well-being.

Concerning the implications of our results, we should consider them in different facets. First, we should keep in mind that sleep disturbances themselves affect daily functioning and may lead to daily impairments in many areas such as hyperactivity, impulsivity and attention, and also mental wellbeing and QoL. One can state that manifest and chronic sleep problems themselves influence ADHD symptomatology. In particular, the correlations between the CSHQ-DE subscale sleep-disordered breathing and impulsivity and hyperactivity should be kept in mind in this context. This association of sleep-disordered breathing and symptoms of ADHD has been discussed in detail by different research groups. ${ }^{51-53}$ These findings also emphasize the importance of cautious clinical practices in diagnosing and treatment of affected children. It is of great importance to distinguish carefully if a child exhibits symptoms of a primary sleep disorder, which should be treated, or if sleep problems might be an expression of a specific ADHD phenotype, as suggested by Owens et al. ${ }^{16}$ Therefore, we recommend running diagnostics separately for ADHD symptomatology and sleep disorders to be able to distinguish between different facets of these disorders. We would recommend using special screening instruments for sleep such as the CSHQ-DE and the sleep self-report to screen potential sleep disorders in children with ADHD andif suspected diagnoses are given - to deepen diagnostics with actigraphy or polysomnography if necessary. ${ }^{44,54}$

Second, a possible impact of comorbid sleep disorders on the ADHD long-term prognosis or risks of relapse seems to be important. Almost two thirds of all children with ADHD show comorbid disorders, which are important influence factors in the successful treatment of those children. ${ }^{8}$ In our view, sleep disorders should also count as such complicating comorbidity which should be carefully observed and diagnosed.

\section{Acknowledgments}

We acknowledge support for the article processing by the Deutsche Forschungsgemeinschaft and the Open Access Publication Fund of Bielefeld University.

\section{Disclosure}

The authors report no conflicts of interest in this work.

\section{References}

1. Breuer D, Döpfner M. Aufmerksamkeitsdefizit-/Hyperaktivitätsstörungen bei drei- bis sechsjährigen in der ärztlichen Praxis - eine bundesweite Befragung. [Attention Deficit/Hyperactivity Disorders amon three-tosix-year-olds treated in medical practices - a national survey]. Z Kinder Jugendpsychiatr Psychother. 2006;34(5):357-365. German.

2. Polanczyk G, Silva de Lima M, Horta B, Biederman J, Rohde L. The worldwide prevalence of ADHD: a systematic review and metaregression analysis. Am J Psychiatry. 2007;164(6):942-948.

3. Willcutt E. The prevalence of DSM-IV attention-deficit/hyperactivity disorder: a meta-analytic review. Neurotherapeutics. 2012;9: 490-499.

4. Nadeau KG. Career choices and workplace challenges for individuals with ADHD. J Clin Psychol. 2005;61(5):607-619.

5. Schmidt S, Petermann F. Entwicklungspsychopathologie der ADHS. [Developmental Psychopathology of ADHD]. Z Klin Psychol Psychiatr Psychother. 2008;56(4):265-274. German.

6. American Academy of Child and Adolescent Psychiatry (AACAP). Practice parameter for the assessment and treatment of children and adolescents with attention-deficit/hyperactivity disorder. $J$ Am Acad Child Adolesc Psychiatry. 2007;46(7):894-921.

7. American Psychiatric Association. Diagnostic and Statistical Manual of Mental Disorders. 5th ed. Washington, DC: American Psychiatric Association; 2013.

8. Gillberg C, Gillberg IC, Rasmussen P, et al. Co-existing disorders in ADHD - implications for diagnosis and intervention. Eur Child Adolesc Psychiatry. 2004;13 (Suppl 1):I80-I92.

9. Jensen PS, Martin D, Cantwell DP. Comorbidity in ADHD: implications for research, practice, and DSM-IV. J Am Acad Child Adolesc Psychiatry. 1997;36(8):1065-1079.

10. Kirov R, Brand S. Sleep problems and their effect in ADHD. Expert Rev Neurother. 2014;14(3):287-299.

11. Biederman J, Faraone SV, Milberger S, et al. Predictors of persistance and remission of ADHD: results from a four-year prospective follow-up study of ADHD children. J Am Acad Child Adolesc Psychiatry. 1996; 35(3):343-351.

12. Cortese S, Faraone SV, Konofal E, Lecendreux M. Sleep in children with attention-deficit/hyperactivity disorder: meta-analysis of subjective and objective studies. J Am Acad Child Adolesc Psychiatry. 2009; 48(9):894-908.

13. Paavonen EJ, Aronen ET, Moilanen I, et al. Sleep problems in schoolaged children: a complimentary view. Acta Paediatr. 2000;89(2): 223-228.

14. Jan Y-W, Yang C-M, Huang Y-S. Comorbidity and confounding factors in attention-deficit/hyperactivity disorder and sleep disorders in children. Psychol Res Behav Manag. 2011;4:139-150.

15. De Crescenzo F, Licchelli S, Ciabattini M, et al. The use of actigraphy in the monitoing of sleep and activity in ADHD: a meta-analysis. Sleep Med Rev. 2016;26:9-20.

16. Owens J, Sangal RB, Sutton VK, Bakken R, Allen AJ, Kelsey D. Subjective and objective measures of sleep in children with attentiondeficit/hyperactivity disorder. Sleep Med. 2009;10:446-456.

17. Kirov R, Banaschweski T, Uebel H, Kinkelbur J, Rothenberger A. REM-sleep alterations in children with co-existence of tic disorders and attention-deficit/hyperactivity disorder: impact of hypermotor symptoms. Eur Child Adoles Psychiatry. 2007;16 (Suppl 1):45-50.

18. Kirov R, Pillar G, Rothenberger A. REM-sleep changes in children with attention-deficit/hyperactivity disorder: methodologic and neurobiologic considerations. Sleep. 2004;27:12-15.

19. Vigliano P, Galloni GB, Bagnasco I, et al. Sleep in children with attention-deficit/hyperactivity disorder (ADHD) before and after 6-month treatment with methylphenidate: a pilot study. Eur J Pediatr. 2016;175:695-704.

20. Owens JA, Mindell JA. Pediatric insomnia. Pediatr Clin North Am. 2011;58:555-569. 
21. Corkum P, Tannock R, Moldofsky H, Hogg-Johnson S, Humphries T. Actigraphy and parental ratings of sleep in children with attentiondeficit/hyperactivity disorder (ADHD). Sleep . 2001;24(3):303-312.

22. Wagner J, Schlarb AA. Subtypes of ADHD and their association with sleep disturbances in children. Somnologie. 2012;16(2):118-123.

23. Gau SS-F, Chiang H-L. Sleep problems and disorders among adolescents with persistant and subthreshold attention-deficit/hyperactivity disorders. Sleep. 2009;32(5):671-679.

24. Meiser-Stedman R. Towards a cognitive-behavioral model of PTSD in children and adolescents. Clin Child Fam Psychol Rev. 2002;5: 217-232.

25. Smedje H, Broman JE, Hetta J. Parents' reports of disturbed sleep in 5-7-year-old Swedish children. Acta Paediatr. 1999;88(8):858-865.

26. Leung AKC, Robson WLM. Nightmares. J Natl Med Assoc. 1993;85: 233-235.

27. Wiechers S, Schlarb AA, Urschitz MS, Eggebrecht E, Schlaud M, Poets CF. Sleep problems and poor academic performance in primary school children. Somnologie. 2011;15(4):243-248.

28. Chiang H-L, Shur-Fen GS, Ni H-C, et al. Association between symptoms and subtypes of attention-deficit hyperactivity disorder and sleep problems/disorders. J Sleep Res. 2010;19:535-545.

29. Li SX, Yu MWM, Lam SP, et al. Frequent nightmares in children: familial aggregation and associations with parent-reported behavioral and mood problems. Sleep. 2011;34(4):487-493.

30. Kirov R, Brand S. Nightmares as predictors of psychiatric disorders in adolescence. Cur Trends Neurol. 2011;5:1-12.

31. Whalen DJ, Gilbert KE, Barch DM, Luby JL, Belden AC. Variation in common preschool sleep problems as an early predictor for depression and anxiety symptom severity across time. JChild Psychol Psychiatry. 2016;58(2):151-159.

32. Alfana C, Ginsburg G, Kingery JN. Sleep-related problems among children and adolescents with anxiety disorders. $J$ Am Acad Child Adolesc Psychiatry. 2007;46(2):224-232.

33. Alfano C, Zakem AH, Costa NM, Taylor LK, Weems CF. Sleep problems and their relation to cognitive factors, anxiety, and depressive symptoms in children and adolescents. Depress Anxiety. 2009;26: 503-512.

34. FletcherFE, Conduit R, Foster-Owens MD, RinehartNJ, Rajaratnam SMW, Cornish KM. The association between anxiety symptoms and sleep in school-aged children: a combined insight from the children's sleep habits questionnaire and actigraphy. Behav Sleep Med. Epub 2016 Jun 2.

35. Gruber R, Sadeh A, Raviv A. Instability of sleep patterns in children with attention-deficit/hyperactivity disorder. $J$ Am Acad Child Adolesc Psychiatry. 2000;39(4):495-501.

36. Virring A, Lambek R, Thomsen PH, Moller LR, Jennum PJ. Disturbed sleep in attention-deficit hyperactivity disorder (ADHD) is not a question of psychiatric comorbidity or ADHD presentation. J Sleep Res. 2016;25:333-340.

37. Becker A, Roessner V, Breuer D, Döpfner M, Rothenberger A. Relationship between quality of life and psychopathological profile: data from an observational study in children with ADHD. Eur Child Adoles Psychiatry. 2011;20 (Suppl 2):S267-S275.

38. Kirov R. REM sleep and dreaming functions beyond reductionism. Behav Brain Sci. 2013;36(6):621-622.

39. McConaughy SH, Achenbach TM. Comorbidity of empirically based syndromes in matched general population and clinical samples. J Child Psychol Psychiatry. 1994;35(6):1141-1157.

Neuropsychiatric Disease and Treatment

\section{Publish your work in this journal}

Neuropsychiatric Disease and Treatment is an international, peerreviewed journal of clinical therapeutics and pharmacology focusing on concise rapid reporting of clinical or pre-clinical studies on a range of neuropsychiatric and neurological disorders. This journal is indexed on PubMed Central, the 'PsycINFO' database and CAS,
40. Escobar R, Soutullo CA, Hervas A, Gastaminza X, Polavieja P, Gilaberte I. Worse quality of life for children with newly diagnosed attention-deficit/hyperactivity disorder, compared with asthmatic and healthy children. Pediatrics. 2005;116(3):e364-e369.

41. Klassen AF, Miller A, Fine S. Health-related quality of life in children and adolescents who hava a diagnosis of attention-deficit/hyperactivity disorder. Pediatrics. 2004;114(5):e541-e547.

42. Petermann F, Petermann UH. Hamburg-Wechsler-Intelligenztest für Kinder - IV (HAWIK-IV). [Hamburg-Wechsler Intelligence Test for children - IV]. Göttingen: Hogrefe; 2007. German.

43. Döpfner M, Görtz-Dorten A. Diagnostik-System für Psychische Störungen im Kindes- und Jugendalter nach ICD-10 und DSM-IV, DISYPS-II. Bern: Verlag Hans Huber; 2008. German.

44. Schlarb AA, Schwerdtle B, Hautzinger M. Validation and psychometric properties of the German version of the Children's Sleep Habits Questionnaire (CSHQ-DE). Somnologie. 2010;14(4):260-266.

45. Arbeitsgruppe Deutsche Child Behavior Checklist. Einführung und Anleitung zur Handauswertung 2. In: von Döpfner M, Plück J, Lenz K, Melchers P, Heim K, editors. Elternfragebogen über das Verhalten von Kindern und Jugendlichen: deutsche Bearbeitung der Child Behavior Checklist (CBCL/4-18). [Diagnostic System for mental disorders in childhood and adolescence according to ICD-10 and DSM-IV]. Aufl. mit deutschen Normen, bearbeitet. Köln: Arbeitsgruppe Kinder-, Jugend- und Familiendiagnostik (KJFD); 1998.

46. American Academy of Sleep Medicine. International Classification of Sleep Disorders. Diagnostic and Coding Manual. 2nd ed. Westchester, IL: American Academy of Sleep Medicine; 2005.

47. Ravens-Sieberer U, Ellert U, Erhart M. Gesundheitsbezogene Lebensqualität von Kindern und Jugendlichen in Deutschland. [Healthrelated Quality of Life of Children and Adolescents in Germany. Norm Data from the German Health Interview and Examination (KiGGS)]. Bundesgesundhbl Gesundheitsforsch Gesundheitsschutz. 2007;50: 810-818. German.

48. Schwerdtle B, Kanis J, Kahl L, Kübler A, Schlarb AA. A new diagnostic tool for children with sleep disorders. Somnologie. 2013;17(3): 199-204.

49. Schwerdtle B, Kanis J, Kübler A, Schlarb AA. The children's sleep comic - psychometrics of a self-rating for childhood insomnia. Child Psychiatry Hum Dev. 2015;47(1):53-63.

50. Gaina A, Sekine M, Chen X, Hamanishi S, Kagamimori S. Validity of child sleep diary questionnaire among junior high school children. J Epidemiol. 2004;14(1):1-4.

51. Garetz SL. Behavior, cognition, and quality of life after adenotonsillectomy for pediatric sleep-disordered breathing: summary of the literature. Otolaryngol Head Neck Surg. 2008;138:S19-S26.

52. Ali NJ, Pitson D, Stradling JR. Sleep disordered breathing: effects of adenotonsillectomy on behaviour and psychological functioning. Eur J Pediatr. 1996;155:56-62.

53. Chervin R, Archbold K, Dillon J, et al. Inattention, hyperactivity, and symptoms of sleep-disordered breathing. Pediatrics. 2002;109(3): 449-456.

54. Schwerdtle B, Roeser K, Kübler A, Schlarb AA. Validierung und psychometrische Eigenschaften der deutschen Version des Sleep Self Report (SSR-DE). [Validation and psychometric properties of the German Version of the Sleep Self Report (SSR-DE)]. Ein Selbstbeurteilungsinstrument zur Erfassung von Schlafstörungen für Kinder von 7-12 Jahren. Somnologie. 2010;14(4):267-274. German.

\section{Dovepress}

and is the official journal of The International Neuropsychiatric Association (INA). The manuscript management system is completely online and includes a very quick and fair peer-review system, which is all easy to use. Visit http://www.dovepress.com/testimonials.php to read real quotes from published authors. 